\title{
TRANSDISCIPLINARIDADE: BREVES NOTAS ACERCA DE LIMITES E FRONTEIRAS DA CIÊNCIA MODERNA ${ }^{1}$
}

\author{
TRANSDISCIPLINARIEDAD: NOTAS BREVES SOBRE LÍMITES Y FRONTERAS \\ DE LA CIENCIA MODERNA
}

\section{TRANSDISCIPLINARITY: BRIEF NOTES ABOUT LIMITS AND FRONTIERS OF MODERN SCIENCE}

HISSA, Cássio Eduardo Viana²

RESUMO: Após quarenta anos de uso, intensificado nos últimos trinta, a palavra transdisciplinaridade tem experimentado movimentos contraditórios que encaminham, ao termo, significados diversos através de conceitos e de práticas originários da própria ciência e da universidade. Alguns desses conceitos e práticas ratificam a compreensão da transdisciplinaridade no âmbito da própria ciência e da universidade modernas. Trata-se da leitura convencional e conservadora que tende a ser hegemônica. Outras, por sua vez, marginais, críticas e criativas, encaminham a concepção da transdisciplinaridade como um exercício de reinvenção da ciência - assim como da própria universidade - estimulado pela reinvenção do próprio sujeito do conhecimento, de modo a lhe permitir a construção de compreensões e interpretações de mundo à altura da complexidade das questões postas pela contemporaneidade. A transdisciplinaridade não poderá ser apenas movimento para além da disciplina, a se dar entre territórios disciplinares ou especializações. A transdisciplinaridade, contraditoriamente, a despeito de manifestar o desejo de movimento para além das disciplinas, somente se realiza enquanto movimento para além da própria ciência. Somente assim a ciência e as disciplinas novamente serão preenchidas de sabedoria e de vida e, ainda, farão sentido libertador os necessários diálogos entre ciência e todos os saberes e práticas que se dão no mundo.

\section{Palavras chave: Transdisciplinaridade; Diálogo entre saberes; Fronteiras da ciência.}

\footnotetext{
1 Texto originário de conferência proferida no II Simpósio Educação Ambiental e Transdisciplinaridade, na Universidade Federal de Goiás, promovido pelo Instituto de Estudos Socioambientais / Núcleo de Pesquisa e Educação Ambiental e Transdisciplinaridade, em 18 de maio de 2011.

${ }^{2}$ Prof. da Universidade Federal de Minas Gerais (UFMG). Doutorado em Geografia, Universidade Estadual Paulista Júlio de Mesquita Filho ( UNESP, 1999). Pós-Doutorado em Sociologia, Centro de Estudos Sociais da Universidade de Coimbra (2006). Mestrado em Demografia, Centro de Desenvolvimento e Planejamento Regional da Universidade Federal de Minas Gerais (1990). Trabalha principalmente com os temas: Epistemologia da Geografia; Espaço e Cultura; Território e sociedade; Diálogo entre Saberes; Teoria do conhecimento. cassioevhissa@terra.com.br
} 
RESUMEN: Después de cuarenta años de uso intensificado en los últimos treinta, la palabra transdisciplinariedad ha experimentado movimientos contradictorios que agregan diversos significados a la expresión, por medio de conceptos y prácticas originadas en la universidad y en la propia ciencia. Algunos de estos conceptos y prácticas confirman la comprensión de la transdisciplinariedad en el contexto de la ciencia y de la universidad moderna. Esta es la lectura convencional y conservadora que tiende a ser hegemónica. Otras, a su vez, marginales, críticas y creativas, presentan el concepto de la transdisciplinariedad como un ejercicio de reinvención de la ciencia — así como de la propia universidad — estimulado por la reinvención del propio sujeto del conocimiento a fin de construyere comprensiones y interpretaciones del mundo al nivel de la complejidad de las cuestiones planteadas por la realidad contemporánea. La transdisciplinariedad no sólo se puede ir más allá de la disciplina, a llenar los territorios entre las disciplinas o especialidades. La transdisciplinariedad, paradójicamente, a pesar de expresar el deseo de ir más allá de las disciplinas, sólo puede realizarse como un movimiento más allá de la propia ciencia. Sólo así las disciplinas y la ciencia serán llenadas de sabiduría e de vida, y, además, también tendrán sentido libertador los necesarios diálogos entre la ciencia y todo el conocimiento y las prácticas que tienen lugar en el mundo.

Palabras-clave: Transdisciplinariedad; Diálogo entre conocimientos; Las fronteras de la ciencia.

\begin{abstract}
After forty years of use, which has intensified over the last thirty, the word transdisciplinarity has crossed contradictory movements, holding various meanings relating to concepts and practices, which originated in the sciences and academia generally. Some of these concepts and practices confirm the understanding of transdisciplinarity in the context of the sciences and modern academia. These are conventional and conservative readings, which tend to be hegemonic. Others, in turn, marginal, critical and creative, present the concept of transdisciplinarity as an exercise in reinventing the sciences - as well as academia itself stimulated by contemporary reality. Transdisciplinarity should not just be seen as a moving beyond a discipline's traditional borders, but also as taking place between discipline's and specializations. Transdisciplinarity, paradoxically, despite expressing a desire to move beyond disciplines, can only come about as a movement beyond the sciences themselves. Only then can the sciences and other disciplines again be filled with wisdom and life, and also convey and practices that take place in the word.
\end{abstract}

Keywords: transdisciplinarity; dialogue between sciences; the frontiers of science. 


\section{INTRODUÇÃO}

Dentre tantas palavras e expressões utilizadas ao longo das últimas décadas do século XX e na primeira do XXI, que expressam a crise da ciência - crise da razão cartesiana, da civilização moderno-ocidental e dos paradigmas modernos - a transdisciplinaridade emerge como palavra-chave, também, como conceito-desafio, como idéia-enigma que, na práxis, de diversas naturezas, explicita suas próprias fragilidades e contradições. Emerge, também, como palavra-mágica, conceito-resposta para os problemas do mundo da ciência e, sobretudo, por tal motivo, incorpora inevitáveis desgastes. Mas a transdisciplinaridade também indica as fragilidades e contradições de certos mundos no mundo: o da ciência, o da razão cartesiana, o do objeto dividido até onde não se pode mais conceber a partilha do mundo (transformado em mundo-objeto) pela ciência - que caracteriza a radicalização absoluta do parcelamento disciplinar —, o dos sujeitos bipartidos em racionalidades e subjetividades. Trata-se de uma manifestação ou de um desejo que explicita reações aos sintomas diversos de mundos adoecidos. Mas, ao explicitar as fragilidades e contradições do mundo, expõe as suas próprias: como paradigma, como método, como prática. Se a proposta do presente exercício é compreender os caminhos da transdisciplinaridade, será preciso compreender o que se pode levar, para o futuro, da idéia que se tem acerca das riquezas e pobrezas - e, portanto, também, dos enriquecimentos e empobrecimentos - da referida palavra-mágica e das práticas que a identificam através de diversas formas e concepções.

A idéia mais simplificada da transdisciplinaridade é apresentada como a convergência da leitura seqüencial de supostos estágios disciplinares e, por sua vez, de conceitos que a eles são correspondentes. ${ }^{3}$ Antes de tudo, entretanto, será preciso dizer de onde é que se profere o discurso em prol da transdisciplinaridade. Fala-se do lugar político da universidade, território da ciência e, mais precisamente, das disciplinas que (não) se comunicam em razão da prevalência de limites hierárquicos e corporativos que dificultam e obstruem possibilidades de mobilidades dos sujeitos do conhecimento e de diálogo interdisciplinar. As disciplinas se organizam de modo a expressar os processos constitutivos da ciência moderna; e a ciência

\footnotetext{
${ }^{3}$ A transdisciplinaridade, para muitos, é interpretada como o último dos estágios de certa seqüência de fases às quais correspondem determinados conceitos: multidisciplinaridade, interdisciplinaridade, transdisciplinaridade. Entretanto, de início poder-se-á afirmar que a multidisciplinaridade não é um estágio a partir do qual viriam os demais. Trata-se de uma invenção, essas seqüências, de modo a permitir a construção de uma imagem de resultado definitivo: o da transgressão dos limites entre as disciplinas.
} 
moderna se faz a partir da negação dialógica de sua pluralidade interna. Portanto, em primeiro lugar, como pressuposto, há a multidisciplinaridade que, por sua vez, não conduz, de modo algum, ao diálogo interdisciplinar. Ela nos diz que há disciplinas e que elas se multiplicam nos interiores do mundo da ciência. Entretanto, ela não tem vida e força crítica para nos dizer que há excesso de disciplinas — sobra de pretensão, e excesso de poder entre os territórios disciplinares que não pode ser legitimado pela sabedoria que se esvai do conhecimento científico transformado em técnica.

A interdisciplinaridade, muitas vezes, é utilizada como palavra-conceito equivalente à transdisciplinaridade. Existem motivos para a referida superposição. A interdisciplinaridade já é a explicitação do desejo de diálogo que não se faz no mundo da pluralidade interna à ciência moderna e no seu lugar político - a universidade moderna que, progressivamente, transforma-se em campo de territórios isolados de conhecimentos especializados. Enquanto desejo de diálogo, entretanto, a interdisciplinaridade não se resolve como diálogo: é manifesto que se esvazia de crítica. Está aqui, portanto, em segundo lugar, algo tomado como certo estágio que, supostamente, antecederia a transdisciplinaridade. Mas a que transdisciplinaridade se refere? É também manifesto? É também manifesto político que, em razão da própria política interna ao mundo da ciência - que é política conservadora que constrói subalternidades - deixa de ser política transformadora para que, na práxis, contrarie o seu próprio discurso de transformação?

Diante das compreensões equivocadas - assim como das compreensões diversas e contraditórias - da palavra, do conceito, da própria prática e abordagem transdisciplinares, é que parece fazer algum sentido o exercício de desvelar o que parece pouco compreendido. Desvelar a abordagem transdisciplinar — e a transdisciplinaridade —, entretanto, assumiria a pretensão de pôr a verdade à mostra e descobrir o que não é visível. Portanto, o exercício de desvelar pode não fazer sentido diante do próprio significado de compreender uma concepção de mundo, filosófico-científica, que questiona a própria concepção hegemônica de ciência. Em outros termos, se a ciência moderna - em sua concepção hegemônica — tem o objetivo de desvelar a realidade e descobrir a verdade do mundo, seria mesmo uma contradição vital aquele exercício epistemológico — que se quer contra-hegemônico — de desvelar a transdisciplinaridade.

Como desvelar, descortinar, essa palavra-enigma, essa palavra-chave prestes a se transformar em chavão? Como descortinar essa idéia de transformação radical de modo a lhe retirar do discurso proferido até pelas vozes mais conservadoras do mundo universitário que 
já se apropriou da palavra da transformação para nada transformar — ou mesmo para encaminhar mais velocidade à construção das subalternidades?

Qual é o sentido de descortinado, desvelado? O desvelado é aquilo do qual se retirou a cortina, névoa, cegueira, obscuridade; e, com isso, lhe concedeu o discernimento, a inteligibilidade. O descortinado é o que se mostra, revelado. Desvelar é fazer conhecer, compreender. Mas não será mesmo ingênua pretensão — sustentada por imaturo verbo - a de desvelar o sentido das coisas que só têm sentido quando a elas se concede o nome por meio da prática? Não será pretensioso esse gesto que se põe a descortinar o que já se mostrou como palavra de ordem - palavra-chave - no mundo do conhecimento em crise?

O propósito da presente reflexão é o de pensar a palavra — transdisciplinaridade —, o conceito e a prática transdisciplinar. O objetivo é o de pensar o discurso a se distanciar da prática e, de tal modo, que a palavra se distancia do seu significado e dos seus sentidos mais motivadores da transformação da ciência. Algumas perguntas poderão servir de abertura a esse exercício, que não poderá ter fim, enquanto, juntos, não estiverem pensamento e prática, intenção e gesto. Se a ciência moderna se expressa mediante o parcelamento do mundo em disciplinas e, por sua vez, se a transdisciplinaridade se quer um projeto de compreensão do mundo para além das disciplinas, como poderá a disciplina se sustentar em si mesma? Como conceber a autonomia da disciplina, no que se refere à leitura particular que faz do mundo? Como conceber a propriedade - particular; disciplinar — de discursos sobre o mundo? Como conceber a hierarquia entre as disciplinas reproduzida e ampliada no âmbito da universidade que, em diversas circunstâncias, apenas por conveniência profere o discurso em prol da transdisciplinaridade? Se a ciência moderna se constitui através do parcelamento do mundo em disciplinas e, por sua vez, a transdisciplinaridade se deseja ver como um projeto de compreensão do mundo para além dos territórios especializados, como poderá a transdisciplinaridade ultrapassar as disciplinas sem que se movimente, também, para além da ciência? Como conceber o diálogo entre as disciplinas sem a concepção do diálogo entre ciência e mundo? Como ler o mundo sem que se esteja nele, dele fazendo parte - e não se esquivando dele, como se fosse possível - , e com ele construindo as vozes da transformação (da ciência, a partir do mundo; e do mundo a partir da ciência)? Como pensar a transdisciplinaridade prisioneira da ciência, já que ela deseja a liberdade das disciplinas que fazem a ciência? Como pensar a liberdade das disciplinas sem pensar a liberdade da ciência - prisioneira dos seus próprios paradigmas de isenção, imparcialidade e de certas neutralidades e objetividades fascistas - e sem conceber o mundo e o homem libertados das 
suas misérias? Todas essas perguntas fazem uma só questão: como pensar a transdisciplinaridade sem questionar as disciplinas — tal como se fizeram — e a ciência moderna?

Não se pretende, aqui, responder às questões postas, mas pensar que a existência delas nos revela em nossas contradições. A existência de tais questões explicita que a reflexão acerca da transdisciplinaridade é: pensar os sujeitos do conhecimento em seu desejo de transformação; compreender que os desejos de transformação dos sujeitos do conhecimento são atravessados pelos seus desejos de transformação do mundo. O discurso da transformação do mundo só poderá ter sentido se estiver articulado ao desejo de transformação dos sujeitos do conhecimento. Desejar transformar o mundo é desejar transformar a si próprio. Caso não seja assim, toda palavra é invadida pela imagem de farsa, conforto e conveniência; e, por sua vez, nessas circunstâncias, todo o gesto carrega, em si, forte desconfiança.

\section{TRANSDISCIPLINARIDADE MODERNA}

Como já se observou, durante as últimas décadas, há diversidade de concepções que encaminham significados à abordagem transdisciplinar e à transdisciplinaridade. Entretanto, todas elas poderão ser reunidas em dois grandes grupos. O primeiro deles, hegemônico, trata a transdisciplinaridade e a abordagem transdisciplinar no âmbito da própria ciência; ou seja, no âmbito que circunscreve as disciplinas e pluralidade disciplinar. Esse primeiro grande e importante grupo - com o qual se identifica, em princípio, a maioria de pesquisadores e de estudiosos originários dos diversos territórios disciplinares - desenvolveu os primeiros passos com o propósito de pensar a ciência nos termos das relações entre as disciplinas. $\mathrm{O}$ segundo deles, por sua vez, trata a transdisciplinaridade e a abordagem transdisciplinar não apenas no âmbito do conhecimento científico, mas, também, no mundo das relações entre a ciência e os saberes diversos. Ambos estão preocupados, certamente, com processos que podem mobilizar a ciência e a disciplina. Entretanto, a presente reflexão caracteriza o primeiro grande grupo como mais alinhado à ciência porque não compreende a transdisciplinaridade como um movimento, também, para além da ciência e, sobretudo, porque utiliza os mesmos paradigmas que referenciam a ciência para pensar a transdisciplinaridade. É por esse motivo que a presente reflexão denomina as referências originárias do primeiro grande grupo como convencionais, a despeito da sua importância histórica. 
A transdisciplinaridade é uma palavra que ainda não consta nos dicionários da língua portuguesa. A despeito disso, é palavra rotineiramente utilizada por muitos na universidade, a partir dos anos de 1970 e, sobretudo, intensamente, a partir das duas últimas décadas do século XX. Ela é anunciada como exercício importante a ser desenvolvido por todos. ${ }^{4}$ Mas tal exercício não se faz; e o discurso é contrariado por práticas que contradizem a concepção de mundo reelaborada conceitualmente ou por práticas que descaracterizam completamente a imagem de transgressão e de subversão à ordem imposta pela ciência moderna. Isso significa que o desenvolvimento de abordagens transdisciplinares é difundido com a justificativa de se construir uma ciência mais crítica e mais próxima do mundo em permanente transformação. A palavra transdisciplinaridade foi utilizada pela primeira vez por Jean Piaget (1970) e, desde então, especialmente a partir da década subseqüente, ela vem sendo discutida à exaustão. Na oportunidade, Jean Piaget concebe a transdisciplinaridade como uma fase subseqüente à interdisciplinaridade. Passadas todas essas décadas, com tantas experiências e debates de natureza epistemológica, poder-se-ia até mesmo compreender a transdisciplinaridade nesses termos. Mas será preciso explicitar problemas e se perguntar de que modo é que se fazem as passagens, pontes e aberturas. Será preciso, também, interrogar as referências convencionais — que ainda servem à ciência moderna - que pensaram a transdisciplinaridade subserviente aos paradigmas que estruturaram o conhecimento científico e a universidade moderna.

A pluralidade no âmbito da ciência — ou pluridisciplinaridade — não é precisamente como o matemático Basarab Nicolescu (1999) optou por compreendê-la: apenas como mais de uma disciplina investindo no estudo de mesmo objeto. Esta, certamente, é uma situação comum, rotineira, que faz parte do processo de produção do conhecimento no âmbito da ciência dividida em disciplinas e, principalmente, quando os limites entre elas não obstruem o trânsito por definitivo. Entretanto, outra leitura deve se somar àquela feita por Basarab Nicolescu. Não se pode construir a interpretação de que as disciplinas têm a autonomia que imaginam ter. Elas desejam ter e se movimentam com esse objetivo. Mas não têm a autonomia que impede a presença ameaçadora da fronteira. Isso significa que os limites interdisciplinares são evidentes, mas eles são artificiais e não garantem que as brilhantes interpretações produzidas pela economia, por exemplo, não estejam permeadas pela presença da sociologia, história, geografia. Isso conduz a interpretação na direção de outros caminhos. Quem poderá dizer que as obras de Karl Marx (1975 [1867]), Friedrich Engels (1986 [1845]),

\footnotetext{
${ }^{4}$ Exercício como visão de mundo reelaborada, como discurso e prática.
} 
Celso Furtado (1982 [1959]), Josué de Castro (1980 [1956]), Sérgio Buarque de Holanda (1983 [1936], 1995 [1957]), dentre tantas outras, não sejam espaço de convergência de variadas disciplinas? Entretanto, elas são defendidas, corporativamente, como pertencentes aos campos disciplinares aos quais supostamente os autores estavam vinculados. O que deve ser focalizado, aqui, é a diversidade política e corporativista de reivindicações de territórios disciplinares pretensamente autônomos. Como não poderá haver absolutas autonomia e propriedade no âmbito do saber, é lugar comum, na prática da produção do conhecimento, certa superposição de leituras do mundo e, ainda, a presença de determinados campos em outros. Isso significa que muito da biologia está, oficialmente, fora dos domínios da biologia. Isso significa, também, que muito da geografia está além dos domínios oficiais da referida disciplina. Por sua vez, o parcelamento do mundo em objetos disciplinares - e da ciência em territórios particulares - compromete a produção do conhecimento e produz esvaziamento de sabedoria. Entretanto, ainda que sejam relativamente raras, são muito fortes as presenças de obras e de autores que transgrediram os limites disciplinares de modo a construir leituras mais complexas do mundo.

Basarab Nicolescu (1999) ainda nos diz que nem os supercomputadores aproximariam as diferentes linguagens proferidas pelas diversas disciplinas. Refletir acerca de tal incapacidade alternativa já é pensar a própria alternativa que, por sua vez, é resultante do próprio ambiente convencional que multiplica as disciplinas e constrói hierarquias de discursos, disciplinas e ofícios. Por sua vez, imaginar que supercomputadores — assim como metodologias e técnicas — resolveriam o apartheid interdisciplinar que impulsiona a ciência convencional é mais do que ingenuidade: é reprodução do conservadorismo, dos paradigmas hegemônicos que fabricaram a ciência moderna a se expressar por meio das disciplinas que se multiplicam e ampliam poderes que reproduzem distâncias entre discursos científicos e entre ciência e todos os saberes do mundo.

Por sua vez, são bastante férteis as reflexões de Basarab Nicolescu (2009) ao se referir à transdisciplinaridade como o movimento que se aloja entre as disciplinas e através delas e não há disciplina que esteja imune a tal movimento. Ainda que não tenha utilizado a expressão, Basarab Nicolescu nos encaminha para o espaço da fronteira e da abertura onde pulsa o território da transgressão ou da subversão dos limites interdisciplinares. Entretanto, Nicolescu Basarab restringe tal movimento através da restrição da própria fronteira, ao pensar a transdisciplinaridade circunscrita aos movimentos entre as disciplinas e no âmbito da ciência. 
É bastante explícita a posição política de Nicolescu Basarab (2009) com respeito à natureza da transdisciplinaridade. Ela não é inimiga da disciplinaridade: é o que ele registra em trechos de sua obra. Cabem aqui algumas interrogações e reflexões. Se não é inimiga ou rival, a transdisciplinaridade é movimento absolutamente contrário ao do parcelamento disciplinar. Portanto, aqui, também, a posição de Nicolescu Basarab é conciliatória e, de alguma maneira, admite restrições ao próprio movimento de ocupação dos espaços fronteiriços interdisciplinares. É certo que a pluralidade ou a diversidade de abordagens é enriquecedora. Entretanto, novamente, devem ser focalizados pelo menos dois pontos de interesse da abordagem transdisciplinar. O primeiro: a diversidade de abordagens não é garantida exatamente pela pluralidade de disciplinas — já que há limitações no processo de produção do conhecimento disciplinar e, também, em determinadas situações, há superposição de abordagens ou de leituras por diferentes campos do conhecimento. $\mathrm{O}$ segundo: se há transdisciplinaridade é movimento entre e para além das disciplinas, é movimento que transforma a disciplina por meio do próprio movimento.

Outro grande pensador que se tornou referência do pensamento transdisciplinar é de Edgar Morin (1999). É inegável a sua fortíssima presença intelectual nos marcantes movimentos contestatórios que se deram em Paris de 1968, assim como nos movimentos referentes à contracultura. É um dos pensadores importantes da ciência contemporânea e desenvolve reflexões marcantes acerca da natureza da transdisciplinaridade. Desenvolve a teoria da complexidade que é compreendida, por ele, como o que é tecido em conjunto, em comunhão. Entretanto, não parece interessar também a Edgar Morin as relações que se dão, inevitavelmente, entre ciência e sociedade, sujeito e mundo. A leitura de Edgar Morin (1999, p. 40), a despeito de pronunciar o desejo de transformação da ciência, é referenciada pelos próprios paradigmas científicos: “[...] se não se sabe conceber cientificamente o cientista e a ciência, como pensar cientificamente a responsabilidade do cientista na sociedade?" Veja-se que, nessa passagem, ele está a pensar a responsabilidade do pesquisador perante a sociedade e o homem; e tal reflexão, segundo ele, deverá ser científica e, por tal motivo, ele anseia por uma ciência da ciência. Percebe-se, com clareza, que não se está pensando a ciência — que se expressa através das disciplinas - e suas fronteiras, espaços de abertura para o mundo.

Há registros preciosos em determinadas passagens de Edgar Morin (1999, p. 135-136): "a ciência nunca teria sido ciência se não tivesse sido transdisciplinar." Entretanto, a transdisciplinaridade, aqui, está circunscrita ao âmbito da ciência. A preocupação é exclusivamente com respeito ao contato e ao desejo de diálogo entre as disciplinas. A 
despeito de todo o desejo de movimento, o que ressalta essa abordagem é o seu aprisionamento aos paradigmas da ciência moderna. É o que se percebe a partir de anotações extraídas de obra de Edgar Morin (1999, p. 40) acerca da teoria e da objetividade: "uma teoria é uma construção [...] lógico-matemática que permite responder a certas perguntas que fazemos [...] à realidade. Uma teoria se fundamenta em dados objetivos [...] [e a] objetividade é uma coisa absolutamente certa." Diante de todas as anotações, a tendência é a de compreender a transdisciplinaridade como pertencente ao circuito da ciência moderna e é assim que preferi adjetivá-la: transdisciplinaridade moderna. ${ }^{5}$

Ao se pensar a transdisciplinaridade, convencionalmente, não se faz referência aos sujeitos, saberes e práticas do mundo. ${ }^{6}$ Faz-se referência às disciplinas científicas e à necessidade de que se ponham em contato e que dialoguem. A transdisciplinaridade não é problema dos homens comuns, das suas práticas e, tampouco, interfere na sua rotina. Mas é interesse de cientistas. No entanto, ela importa para a ciência - ainda que, na prática, apenas para uma minoria dos cientistas — - sobretudo se estiver confinada ao âmbito da universidade e da própria ciência. A mistura interdisciplinar é saudável, poderão dizer os que proferem o discurso em prol da transdisciplinaridade; entretanto, quando é assim, quase nunca se faz referência à mistura entre o conhecimento científico e os saberes que circulam nas sociedades. ${ }^{7}$ Faz-se referência, especialmente, ao diálogo entre as disciplinas.

A poesia não é uma disciplina científica, conforme as referências que estruturam o conhecimento científico. Isso significa que o poeta não é cientista. $O$ jardineiro também não é. $\mathrm{O}$ artesanato não é ciência, assim como o artesão não é cientista. $\mathrm{O}$ músico e o pintor não são cientistas. Os povos indígenas dispersos pelo mundo desenvolveram e acumularam saberes que não são científicos, ainda que sejam de interesse da ciência. ${ }^{8}$ Os saberes dos quintais e do mundo rural também não são científicos, ainda que, também, possam ser de interesse da ciência. Portanto, a transdisciplinaridade é manifestação de desejo de diálogo interdisciplinar e, conforme os paradigmas que estruturam a ciência moderna, o referido diálogo dar-se-ia no

\footnotetext{
${ }^{5}$ Cf. HISSA (2008).

${ }^{6}$ Em muitas circunstâncias e situações, já suficientemente postas — para parcelas da sociedade, pela mídia, pela literatura acadêmica - para a compreensão clara da questão, quando se consideram os mais diversos saberes e práticas, estes nem sempre são legitimados, mas usurpados.

7 Em determinadas pesquisas acadêmicas, quando há estreitamento entre conhecimento científico e saberes diversos, o que se percebe, antes de tudo, é a desconfiança entre as partes: conhecedores tradicionais ou populares e farmacêuticos, por exemplo, no trato com as plantas medicinais. Cf. COUTINNHO (2010).

${ }^{8}$ Mas qual tem sido o caráter predominante desse interesse da ciência pelos saberes diversos do mundo? O que se percebe, rotineiramente, na maioria das situações, é o interesse científico-comercial que expropria os saberes tradicionais e, sob a forma da multiplicação de patentes, também, é reproduzido e banalizado o exercício da pirataria. Cf. GOMES (2009).
} 
âmbito da ciência. Ele é pensado, por cientistas, para ser assim. Os povos indígenas não pensam a transdisciplinaridade como um exercício que aperfeiçoaria a produção dos seus saberes e de suas práticas. A transdisciplinaridade é um problema da ciência, tal como ela se percebeu - através dos seus sujeitos - em sua precariedade e experimentando as suas crises mais contemporâneas. Entretanto, talvez, nos falte sabedoria para pensar a força da mistura e a fronteira como território fértil da ciência.

Nem sempre um sábio é cientista. Quase nunca um cientista é sábio: a afirmativa é forte? ${ }^{9}$ Pode ser, mas quase sempre os cientistas são técnicos especializados. Não causa estranheza que muito da sabedoria esteja fora dos circuitos modernos e sofisticados da ciência? Não causa incômodo o fato de que a ciência se esvaziou de sabedoria — não se deixando afetar pelos saberes e afetos do mundo - precisamente por (e para) ser conhecimento esvaziado de mundo? Por onde caminha a inteligência? Epicarmo diz: é $a$ inteligência que vê e escuta; todo o resto é surdo e cego. De que são feitos os olhos de ciência? Apenas de retina? Não são feitos de sensibilidade, experimentação de mundo, imaginação, criatividade, emoção? O que se pode dizer acerca da inteligência auditiva da ciência? Quando determinada pesquisa anuncia que dará voz, por exemplo, a determinados grupos sociais - sujeitos urbanos, por exemplo, em precárias condições de vida em seu espaço abandonado de cidade —, o que se pode intuir, no mínimo, é que ela se julga portadora de poderes que concedem um lugar às vozes do mundo. Mas a ciência não pede palavra para produzir saber com os referidos e hipotéticos sujeitos que são, em princípio, os mais fortemente interessados. Ela concede alguma espécie de espaço para alguma espécie de palavra. ${ }^{10}$ Não é a palavra que chega, sem restrições ou censura, e diz: estou aqui porque preciso estar ou porque aqui é também meu lugar. Quando isso se dá, raramente, estaremos aqui a discutir a presença da palavra invasora, do sujeito invasor, que se movimenta na direção do território da pesquisa científica em que não há espaço para as interpretações do mundo construídas pelos próprios sujeitos do mundo que não são cientistas. Podem ser

\footnotetext{
${ }^{9}$ Sábio é uma palavra perdida como substantivo, na universidade moderna. Algumas atitudes são adjetivadas: sábias. Não é por modéstia que o cientista convencional não se assume como sábio. Ele se percebe, na maioria das situações, como técnico ou como especialista. Tal percepção é compatível com a leitura que a sociedade faz dos cientistas: são especialistas, técnicos. Parece haver conhecimento do que se perdeu ao longo da história da modernidade na ciência e na universidade.

${ }^{10}$ Caberão, aqui, sempre, questões fundamentais a discutir e pensar enquanto se reflete sobre abordagens transdisciplinares. É a ciência que concede a palavra às vozes do mundo? Sem a ciência não existirão as vozes do mundo? Não será muita pretensão da ciência fazer com que as vozes do mundo existam para dizer, alto, tudo acerca do que pesa e tudo acerca do peso do mundo? Elas já não existem? Não estamos vivendo uma extensão histórica do fascismo que prefere ignorar as vozes do mundo e, sobretudo, acreditar no poder da ciência de fazer com que as vozes passem a dizer algo quando já dizem?
} 
poetas, filósofos, escritores, indígenas, trabalhadores do campo, ambulantes, favelados, músicos, mas não são cientistas e, por mais que vivam no território pesquisado, não fazem parte do território político da pesquisa que profere o discurso da objetividade e da neutralidade, mas que toma partido e, convencionalmente, tende para o lado dos que são mais fortes. A ciência procura sobreviver. Mas procura o caminho que não constrói a vida. Por tal motivo, também, da crise da razão cartesiana emerge o desejo de reinvenção da ciência e dos sujeitos do conhecimento.

A ciência moderna se desenvolve através de certo discurso que resulta em algumas práticas que a consolidaram ao longo da história: apartheid sujeito-objeto; suposta leitura imparcial e objetiva do mundo; delimitação dos campos do conhecimento; concepção de mundo que o transforma em objeto-mundo; parcelamento do objeto-mundo pelas diversas disciplinas. A expectativa é a de desmembramento do todo e de tudo de modo a construir a análise explicativa da realidade: o seu desvelar. A expectativa é a de que o conhecimento disciplinar, especializado, possa fornecer a análise que se aproxima da verdade acerca das coisas e do mundo fora do eu: a denominada realidade. ${ }^{11}$ A compreensão da transdisciplinaridade, das práticas e das abordagens transdisciplinares não estará articulada à concepção de povoamento das fronteiras da ciência — onde se dariam os seus diálogos com o mundo e entre as disciplinas?

\section{CONSIDERAÇÕES FINAIS: TRANSDISCIPLINARIDADE E DIÁLOGO ENTRE SABERES}

Duas questões de abertura para a reflexão: como é que se concebe a transdisciplinaridade sem a interferência do mundo e sem que os sujeitos do conhecimento se deixem afetar pelo mundo e pelas suas mais fortes questões? Como é que se pode pensar em determinadas práticas - como a que se refere à educação ambiental e ao desenvolvimento sustentável quando são referenciados pela abordagem transdisciplinar — sem que os valores da cultura moderno-ocidental sejam discutidos e questionados? Talvez, mais: sem que os

\footnotetext{
${ }^{11}$ Há uma vastíssima literatura que aborda a história da constituição da ciência moderna. Muito dessa literatura é desenvolvida no âmbito da filosofia da ciência, mas, também, é discutida por epistemologias disciplinares e epistemologias diversas. Nessa literatura está também inserida a crítica a todo esse processo, assim como encaminhamentos de alternativas para a superação de problemas. Ver, por exemplo, as seguintes obras: ABBAGNANO (1982, 2006), BUARQUE (1994), CALVINO (1991), CAPRA (2000, 2001), CHAUÍ (2001), DAMÁSIO (1996), FREIRE (2002), LALANDE (1999), MORIN (1999), REALE; ANTISERI (1990), SACKS (1995, 1997, 1998, 2003), SANTOS, B. (1987, 1989, 2006), SANTOS, B.; MENESES (2010), RIBEIRO (2003), ROSSI (2001), SANTOS, M. (2000), TAVARES (2006).
} 
sujeitos do mundo ampliem as vozes da ciência que deseja transformar o mundo. A ciência deseja transformar o mundo?

O que se deve pensar, diante de toda a discussão conceitual acerca da abordagem transdisciplinar, é que o diálogo entre disciplinas pressupõe, antes de tudo, o trânsito interdisciplinar dos sujeitos do conhecimento. Portanto, desde já, aqui, será sempre bom desconfiar de que as disciplinas não dialogam entre si e por si só. São os sujeitos do conhecimento que, provocando o seu próprio trânsito entre os diversos campos disciplinares, produzem abordagens disciplinares. Para que tal movimento se realize, será preciso considerar, também, a necessária formação transdisciplinar dos sujeitos que, por sua vez, é dificultada ou obstruída pela orientação disciplinar que recebem na universidade das especialidades.

Por sua vez, o diálogo entre disciplinas, saberes e práticas do mundo pressupõe o trânsito dos sujeitos do conhecimento entre disciplinas, mas, também, entre lugares que se põem para além da ciência. Portanto, será sempre bom refletir sobre a seguinte afirmativa: os sujeitos do conhecimento são, antes de tudo, também, sujeitos do mundo. Paulo Freire (1985) preferiu dizer isso de outro modo: a leitura do mundo é anterior à leitura da palavra. Isso significa que, mergulhados no mundo, os sujeitos do conhecimento deverão construir interpretações do mundo, através da palavra, que são permeadas pela sua condição de sujeitos do mundo. Está, aqui, esta presença contraditoriamente estranha em nós, e que nos desafia; esse corpo de mundo, em nós, que nos provoca enquanto sujeitos do conhecimento! Não será prudente reconhecer e aceitar, em nós, o que há de mundo em nós para que possamos interpretá-lo como sujeitos do conhecimento?

O mundo é a única e rica possibilidade de mediação entre as disciplinas, conforme nos diz, também, Milton Santos (2000). As especialidades são a expressão da transformação do mundo em objeto-mundo recortado em fatias, e tal como nos lembra Milton Santos (2000, p. 49), “[...] todas as disciplinas têm sua relação com o mundo.” Todas as disciplinas vão ao mundo para dele recolher os objetos de estudo que lhes estruturam como território do conhecimento. Isso significa que, contraditoriamente, vai-se ao mundo para que dele sejam recortados os objetos que fazem as disciplinas e, também, para que sejam viabilizadas as possibilidades de interlocução transdisciplinar através dos sujeitos do conhecimento. Não há possibilidade de diálogo direto entre disciplinas e entre ciência e saberes que circulam na sociedade. Milton Santos (2000, p. 49): “o que faz com que uma disciplina se relacione com as demais é o mundo, o mesmo mundo que, no seu movimento, faz com que a minha 
disciplina se transforme." É esse trecho de obra que Milton Santos (2000) que aqui se reinterpreta: a transdisciplinaridade não é algo que possa se referir às disciplinas, mas ao mundo. Milton Santos (2000, p. 49) acrescenta: “o mundo é que permite que se estabeleça um discurso inteligível, um canal de comunicação entre as disciplinas." Portanto, caso se compreenda a transdisciplinaridade como movimento de abertura da disciplina e da ciência, nos territórios de fronteira ela se realiza como transgressão aos limites interdisciplinares e aos limites entre ciência e mundo. ${ }^{12}$ São nos territórios da fronteira da ciência que a disciplina encontra a sua própria abertura e possibilidades de diálogo: com as disciplinas científicas e com os diversos saberes não científicos. Somente assim poderemos imaginar uma ciência plena de mundo, mais prática, que não desperdice as experiências e os saberes do mundo, como optou por dizer Boaventura de Sousa Santos (2006) que, nesses termos, nos faz pensar a transdisciplinaridade incorporada à ecologia de saberes — teoria por ele desenvolvida.

É percorrendo tais caminhos que deveremos compreender a transdisciplinaridade como reveladora de uma disposição e, por sua vez, também, de uma implicação do sujeito cujo sentido é o do engajamento político. Assim, na abordagem transdisciplinar que se insere no diálogo entre conhecimentos científicos e saberes diversos existem possibilidades de se evocar o mundo a ser trabalhado com os sujeitos. Quando assim se faz, na pesquisa que se abre, revelam-se vozes que transformam (não apenas a pesquisa) a disciplina e a ciência por meio da transformação dos sujeitos (que desejam se transformar). Aqui, falamos, portanto, da arte do diálogo na pesquisa, na ciência. Como é que se pode instituir a arte na ciência? A arte é resistência, ainda que formas de expressão artística tenham sucumbido ao mercado - e deixaram de ser resistência. A arte do diálogo implica uma disponibilidade e uma disposição. Mas, aqui, ao pensar a arte do diálogo é demandada uma implicação do sujeito que se deixa afetar e seu engajamento político. Mas como povoar o território asséptico da ciência por esse diálogo que, sempre, é diálogo político? Portanto, estamos aqui refletindo sobre a ciência reinventada e sobre sujeitos do conhecimento que se repensam e se transformam - a partir do mundo e não a partir de si próprios. Não faz sentido algum pensar a reinvenção da ciência a partir dos valores da própria ciência que se deixou invadir pelo mercado de idéias e que, na contemporaneidade, com tantos problemas que se perpetuam no mundo, ainda é pensada nos termos em que foi concebida: com uma suposta elegância asséptica, antes de tudo; sem brilho cultural transformador, antes de mais nada. Somente a partir de uma ciência plena de mundo é

\footnotetext{
${ }^{12}$ Enquanto os limites voltam-se para dentro dos territórios — das disciplinas e da ciência —, as fronteiras estão voltadas para fora. Cf. HISSA (2002).
} 
que temáticas como bioética e tecnologias limpas poderiam ser pensadas também nos termos em que os valores da vida digna prevaleceriam sobre os valores de mercado.

Finalmente, o exercício reflexivo que se propõe a compreender a transdisciplinaridade, já superada a primeira década do século XXI, passados quarenta anos de existência do desejo de diálogo interdisciplinar, é exercício de reflexão acerca dos nossos limites e dos limites da ciência moderna. Discutir a transdisciplinaridade é por à mostra os limites que carregamos em nós - freqüentemente desconhecidos ou ignorados pela nossa cegueira científica - e que reproduzimos na universidade com toda a potência da obstrução do outro, da negação do outro e, conseqüentemente, de nós mesmos; é revelar limites que carregamos, mas queremos no outro, não em nós mesmos.

\section{REFERÊNCIAS BIBLOGRÁFICAS}

ABBAGNANO, Nicola. Dicionário de filosofia. São Paulo: Editora Mestre Jou, 1982.

ABBAGNANO, Nicola. História da filosofia. 6. ed. 12 v. Lisboa: Editorial Presença, 2006.

BUARQUE, Cristovam. A aventura da universidade. 2. ed. São Paulo: Paz e Terra / Editora UNESP, 1994.

CALVINO, Italo. Seis propostas para o próximo milênio: lições americanas. São Paulo: Companhia das Letras, 1991.

CAPRA, Fritjof. $O$ ponto de mutação: a ciência, a sociedade e a cultura emergente. 22. ed. São Paulo: Cultrix, 2001.

CAPRA, Fritjof. $O$ tao da física: um paralelo entre a física moderna e o misticismo oriental. 20. ed. São Paulo: Cultrix, 2000.

CASTRO, Josué. Geografia da fome: o dilema brasileiro: pão ou aço. 10. ed. Rio de Janeiro: Antares; Achiamé, 1980 [1956].

CHAUÍ, Marilena. Escritos sobre a universidade. São Paulo: Editora UNESP, 2001.

COUTINHO, Maura Neves. Agricultura urbana: práticas populares e sua inserção em políticas públicas. Dissertação (Mestrado em Geografia). Instituto de Geociências, Universidade Federal de Minas Gerais, Belo Horizonte, 2010.

DAMÁSIO, António. O erro de Descartes: emoção, razão e o cérebro humano. São Paulo: Companhia das Letras, 1996.

ENGELS, Friedrich. A situação da classe trabalhadora na Inglaterra. São Paulo: Global, 1986 [1845].

FREIRE, Paulo. Pedagogia do oprimido. 32. ed. São Paulo: Paz e Terra, 2002 [1970].

FREIRE, Paulo. A importância do ato de ler. São Paulo: Cortez, 1985.

FURTADO, Celso. Formação econômica do Brasil. São Paulo: Companhia Editora Nacional, 1982 [1959]. 
GOMES, Ângela Maria da Silva. Rotas e diálogos de saberes da etnobotânica transatlântica negroafricana: terreiros, quilombos, quintais da Grande BH. Tese (Doutorado em Geografia). Instituto de Geociências, Universidade Federal de Minas Gerais, Belo Horizonte, 2009.

HISSA, Cássio E. Viana. A mobilidade das fronteiras. Belo Horizonte: Editora UFMG, 2002.

HISSA, Cássio E. Viana. Saberes ambientais: desafios para o conhecimento disciplinar. Belo Horizonte: Editora UFMG, 2008.

HOLANDA, Sérgio Buarque de. Caminhos e fronteiras. São Paulo: Companhia das Letras, 1995 [1957].

HOLANDA, Sérgio Buarque de. Raízes do Brasil. 12. ed. Rio de Janeiro: José Olympio, 1983 [1936].

LALANDE, André. Vocabulário técnico e crítico da filosofia. São Paulo: Martins Fontes, 1999.

MARX, Karl. O capital: crítica da economia política. 3. ed. 6 v. Rio de Janeiro: Civilização Brasileira, 1975 [1867].

MORIN, Edgar. Ciência com consciência. 3. ed. Rio de Janeiro: Bertrand Brasil, 1999.

NICOLESCU, Basarab. Contradição, lógica do terceiro incluído e níveis de realidade. Disponível em: $\quad<$ http://www.cetrans.com.br/textos/contradicao-logica-do-terceiro-incluido-e-niveis-derealidade.pdf >. Acesso em: 02 abr. 2011. [Trabalho apresentado em: Aleliers sur La contradiction: nouvelle force de développement en science et societé. École n.s. des mines. Saint-Etiene, 19-21 mar. 2009].

NICOLESCU, Basarab. Manifesto da transdisciplinaridade. 4. ed. São Paulo: Editora TRIOM, 1999.

PIAGET, Jean. Colloque sur l'interdisciplinarité. Nice: OCD, 1970.

REALE, Giovanni; ANTISERI, Dario. História da filosofia. 3 v. São Paulo: PAULUS, 1990.

RIBEIRO, Renato Janine. A universidade e a vida atual: Fellini não via filmes. Rio de Janeiro: Campus, 2003.

ROSSI, Paolo. O nascimento da ciência moderna na Europa. Bauru: Edusc, 2001.

SACKS, Oliver. Com uma perna só. São Paulo: Companhia das Letras, 2003.

SACKS, Oliver. O homem que confundiu sua mulher com um chapéu. São Paulo: Companhia das Letras, 1997.

SACKS, Oliver. Vendo vozes: uma viagem ao mundo dos surdos. São Paulo: Companhia das Letras, 1998.

SACKS, Oliver. Um antropólogo em Marte: sete histórias paradoxais. São Paulo: Companhia das Letras, 1995.

SANTOS, Boaventura de Sousa. A gramática do tempo: para uma nova cultura política. São Paulo: Cortez, 2006.

SANTOS, Boaventura de Sousa. Introdução a uma ciência pós-moderna. Rio de Janeiro: Graal, 1989.

SANTOS, Boaventura de Sousa. Um discurso sobre as ciências. Porto: Afrontamento, 1987.

SANTOS, Boaventura de Sousa; MENESES, Maria Paula. (Org.) Epistemologias do Sul. São Paulo: Cortez, 2010.

SANTOS, Milton. Território e sociedade: entrevista com Milton Santos. São Paulo: Perseu Abramo, 2000.

TAVARES, Gonçalo. Breves notas sobre ciência. Lisboa: Relógio D’Água, 2006. 